\title{
Elevated Intracranial Pressure Associated with Hypermetabolism in Isolated Head Trauma
}

\author{
M. N. Bucci, R. E. Dechert, D. K. Arnoldi, J. Campbell, J. E. McGillicuddy, and R. H. Bartlett \\ Department of Surgery, Sections of Neurosurgery and General Surgery, The University of Michigan, Ann Arbor, Michigan, U.S.A.
}

\section{Summary}

Both metabolic rate and protein catabolism are known to increase following severe head trauma, but the etiology of this hypermetabolism is unknown. To further investigate the problem, we studied the metabolism of 17 patients with indirect calorimetry who had severe craniocerebral trauma only and who required ICP monitoring for management. Patients were studied daily and immediately after ICP spikes greater than $20 \mathrm{~mm} \mathrm{Hg}$, prior to treatment with hyperventilation, osmotic diuretics, or barbiturates. Oxygen consumption $\left(\mathrm{VO}_{2}\right)$ was correlated with ICP. Two groups of patients were identified. Group I patients were treated with hyperventilation and osmotic diuretics while Group II patients additionally received cerebral metabolic depressants. Group I had a significant correlation coefficent between $\mathrm{VO}_{2}$ and ICP. Significant hypercatabolism early in the post trauma period was demonstrated by increased urine urea nitrogen. Our observations suggest that in patients with craniocerebral trauma, elevated ICP is associated with increased oxygen consumption, protein catabolism and systemic hypermetabolism. $\mathrm{Ce}$ rebral metabolic depressants blunted increases in $\mathrm{VO}_{2}$ which were seen with elevated ICP.

Keywords: Head injury; intracranial pressure; metabolism; nitrogen balance; oxygen consumption.

\section{Introduction}

Severe head injury results in systematic hypermetabolism similar to that seen in patients with large body surface burns and sepsis ${ }^{6,18}$. This state is characterized by increased oxygen consumption and increased protein catabolism. Previous metabolic studies have included multiple trauma victims ${ }^{1,2,13}$. However, few studies have reported metabolic changes in patients with head injury alone $e^{3,5,6,7,8,9,18}$. The cause of this increased metabolism is unknown ${ }^{7}$. To further delineate this problem, we investigated the effects of increased intracranial pressure on oxygen consumption and overall metabolism in patients with severe craniocerebral trauma.

\section{Materials and Methods}

The metabolic rate of 17 patients with severe craniocerebral trauma only, who required ICP monitoring, were studied in a nonrandomized prospective fashion. Initial Glasgow Coma Scale Score was 8 or less for all patients. Patients with multiple trauma or other systemic injuries were excluded from this study. The period of the study was from August, 1985 through September, 1986. All patients had either subarachnoid screws, or ventricular catheters placed to monitor intracranial pressure. There were 14 males and 3 females in this group. The age range was 18 to 67 years with an average of 27. Temperature, blood pressure, respiratory rate and heart rate were monitored hourly in the Intensive Care Unit. Intracranial pressure recording was monitored continuously.

Energy expenditure is determined by indirect calorimetry using the Waters MRM 6,000 calorimeter (Waters Instrument, Minneapolis, Minnesota). The calorimeter uses the closed-circuit technique for determination of oxygen consumption $\left(\mathrm{VO}_{2}\right)$. Therefore, $\mathrm{VO}_{2}$ is a direct volumetric analysis of oxygen removed from the system. Carbon dioxide production $\left(\mathrm{VO}_{2}\right)$ is determined simultaneously by mixed expired gas analysis. The $\mathrm{VO}_{2}$ and $\mathrm{VCO}_{2}$ are utilized to determine energy expenditure by the Weir equation ${ }^{15} . \mathrm{VO}_{2}, \mathrm{VCO}_{2}$ and resting energy expenditure (REE) are normalized for the individual's body surface areas.

Data were obtained daily at baseline ICP levels and immediately after ICP spikes greater than $20 \mathrm{~mm} \mathrm{Hg}$. Patients were studied prior to treatment with hyperventilation, osmotic diuretics or barbiturates. The study time throughout the period of the ICP spike was usually 20 minutes or greater. Urine was collected for 24 hour urea nitrogen determination. None of the patients received corticosteroids. Data were omitted from patients with elevated body temperature greater than $38^{\circ} \mathrm{C}$.

Patients were studied throughout the duration of ICP monitoring on an average of 7 days, with a range of 4 to 30 days. Patients received IV fluids only in the first 48 hours. After 48 hours, all patients received enteral feeding consisting of $16 \%$ protein, $21 \%$ fat and $63 \%$ carbohydrate. Approximately $35 \mathrm{kcal} / \mathrm{kg}$ body weight were administered each day.

Of the 17 patients, 5 underwent craniotomy for gunshot wound (1), subdural hematoma (3), and extradural hematoma (1). The remaining 12 had severe closed head injuries. ICP ranged between 1 and $41 \mathrm{~mm} \mathrm{Hg}$. $\mathrm{VO}_{2}$ was expressed as $\mathrm{ml} / \mathrm{min} / \mathrm{M}^{2}$.

Linear regression analysis was used to determine the relationship 
between ICP and $\mathrm{VO}_{2}$, and the two-tailed Student's t-test was used to compare $\mathrm{VO}_{2}$ and $\mathrm{REE}$ between groups of patients.

\section{Results}

One hundred and nineteen combined measurements of ICP and $\mathrm{VO}_{2}$ were analyzed. Seventy-four measurements were made in 13 of 17 patients in group I. $\mathrm{VO}_{2}$ correlated directly with ICP with a correlation coefficient of 0.74 which was nearly linear (Fig. 1). Forty-five measurements were made in the remaining

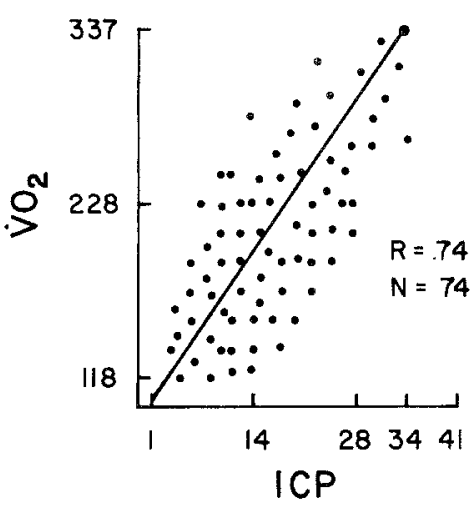

Fig. 1. Graph depicting the relationship between ICP $(\mathrm{mm} \mathrm{Hg})$ versus $\mathrm{VO}_{2}\left(\mathrm{ml} / \mathrm{min} / \mathrm{m}^{2}\right)$ in 13 of 17 patients, with a correlation coefficient of 0.74 . Each data point represents a single measurement among thirteen patients

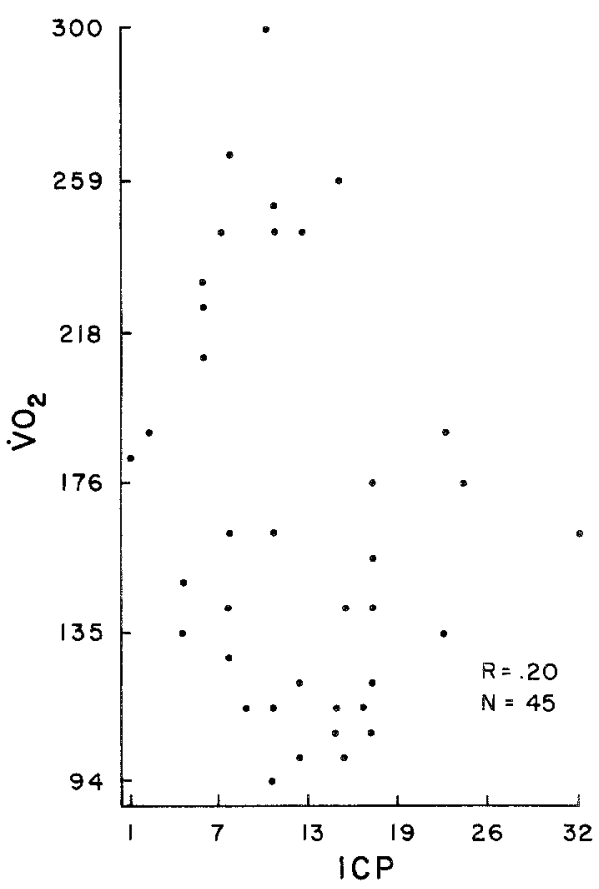

Fig. 2. Graph of ICP versus $\mathrm{VO}_{2}$ in 4 of 17 patients who received cerebral depressants, showing a correlation coefficient of 0.20

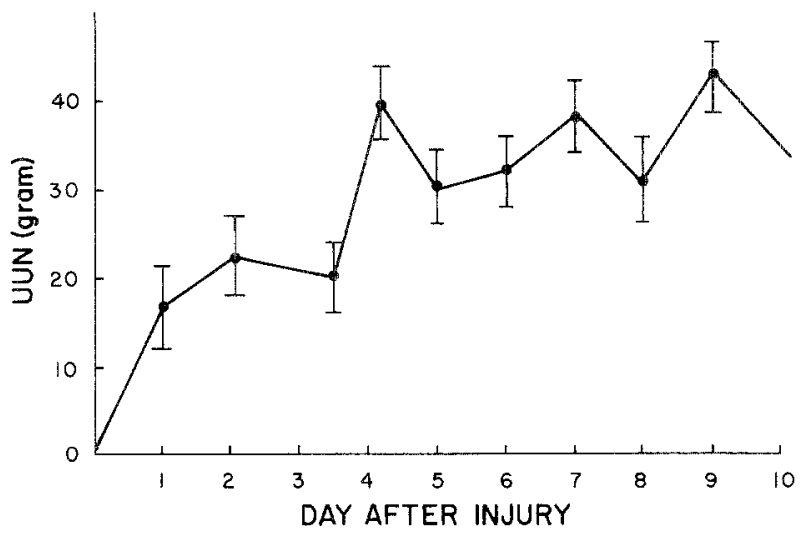

Fig. 3. Graph depicting UUN excretion expressed in grams, showing a rise within the first 10 days following injury

4 of 17 patients in group II. In this group, 2 patients were treated with pentobarbital coma, and 2 received large doses of morphine sulphate. ICP did not correlate in this subgroup, evidenced by a correlation coefficient of 0.20 (Fig. 2). The difference between these two groups was significant ( $\mathrm{p}$ 0.05). Carbon dioxide production was compared among the 17 patients, but no specific pattern could be determined due to the use of hyperventilation in the majority of these patients.

Resting energy expenditure (REE) was determined for each measurement. In group II the mean REE was $991.18 \mathrm{kcal} / \mathrm{m}^{2}$, while in group I, the mean REE was $1383.40 \mathrm{kcal} / \mathrm{m}^{2}$ with a range of 874.66 to $3962.00 \mathrm{kcal} /$ $\mathrm{m}^{2}$. The difference between group I and group II was significant $(\mathrm{p}<0.05)$.

The cumulative caloric balance was analyzed. By day 7 after injury, all patients were in negative caloric balance with a range between negative 6,000 and negative 18,000 calories. There were no differences in oxygen consumption among the various injury types, or among the operated versus nonoperated patients. A urine urea mitrogen (UUN) rise was noted within the first 8 to 10 days irrespective of injury type, surgery, or nutritional support (Fig. 3).

Glasgow Coma Scale Score (GCS) did not correlate with $\mathrm{VO}_{2}$ in either group. In general, lower GCS correlated with lower REE for both groups, however, this was not significant.

\section{Discussion}

Reports of metabolism in head injury date back to 1947 when Drew et al. first reported on metabolism and nitrogen balance studies in 12 post craniotomy patients ${ }^{10}$. They suggested that the prognosis in these patients might be favourably affected by positive ni- 
trogen balance. In 1983 the first prospective randomized control trial of metabolism and head injury was carried out by Rapp and Young ${ }^{14}$. They had 38 patients with severe head trauma who were randomized to receive either total parenteral nutrition or enteral feedings. They measured outcome in terms of survival. The group which had initial total parenteral nutrition had a statistically significant increase in survival compared to the control feeding group. Overall, the total parenteral nutrition group had significantly more caloric intake than the enteral group. Both groups, however, had persistently negative nitrogen balance. They excluded severe extracranial injuries, but included other non-life threatening injuries in this group of patients.

In 1984, Clifton reported his study of 14 head injured patients treated with steroids who were given enteral feedings ${ }^{6}$. Except for two patients who had long bone fractures and one patient with facial fractures, these patients had no major systemic injuries. Indirect calorimetry was measured: head injured patients had metabolic responsed similar to burn patients with an approximate 20 to $40 \%$ body surface burn.

Waters reported 11 patients with severe head injury who had cumulative caloric deficits ranging between 2,500 and 25,000 calories $^{18}$. There was a suggestion of improved clinical outcome with smaller caloric deficits.

In 1985, Clifton reported a second study of enteral hyperalimentation in 20 consecutive head injured patients ${ }^{5}$. This was a pure head injury group. The patients received approximately 3,500 kcal/day. Despite this, the patient's weight fell an average of approximately $15 \%$ by the second week. Total albumin fell also and the urine urea nitrogen increased by the second week. They recommended approximately $50 \mathrm{kcal} / \mathrm{kg} /$ day of nutritional support.

Young et al. reported 16 patients with head injury, 6 of whom had multiple trauma ${ }^{19}$. The mean nitrogen balance was negative in all but two patients despite caloric balance by the second week. They found that albumin dropped by a factor of approximately $33 \%$ and that the weight loss average was approximately 15 pounds by the end of the second week.

Recently, Fruin studied metabolism using indirect calorimetry in 15 non-steroid treated head injured patients ${ }^{11}$. Various clinical markers were assessed which were used to predict caloric requirements. Excessive motor activity correlated significantly with increased caloric needs. This was not a pure injury group because other associated injuries and infections were documented.

Clifton et al. suggested a practical guide to estimate energy expenditure in head injured patients ${ }^{4}$. The percentage of resting metabolic energy expenditure was determined to be a function of the Glasgow Coma Scale Score, heart rate, and days since injury. In noncomatose patients, the predictive ability of their nomogram was less strong due to the inability to measure truly rested values. Levels of caloric expenditure varied from factors such as temperature, Glasgow Coma Scale score, activity, muscle tone, and the time of measurement after injury.

Deutschman reported that closed head injury patients initially were hypermetabolic, however, the process appeared to resolve by one week ${ }^{8,9}$. These patients then assumed the profile of a starving patient.

Elevated ICP correlated with oxygen consumption in our previous study and in this expanded one ${ }^{3}$. In our patients who received large doses of metabolic depressants (Group II), this correlation did not hold. The cerebral metabolic depressants blunted increases in $\mathrm{VO}_{2}$ which were seen with elevated ICP. It is possible that a catecholamine surge occuring as a result of increased ICP is responsible for the overall hypermetabolism ${ }^{7}$.

Oxygen consumption was measured continuously as a change in the level of the spirometer in our MRM 6,000 calorimeter. This mean oxygen consumption was a direct volumetric measurement and, therefore, highly accurate. Caloric expenditure and overall energy balance were normalized from these direct measurements.

Urine urea nitrogen excretion rose within the first 10 days, similar to data from Young's group ${ }^{14}$. Our patients became significantly catabolic early in their course and urinary urea nitrogen increased with increasing protein in the diet as shown by Clifton ${ }^{5}$. More data points are needed in the recovery stage to determine the overall effect of negative nitrogen balance. Previous reports indicate that negative nitrogen balance is not necessarily a detriment to the patient's overall outcome $\mathrm{e}^{4,12}$, and that it is extremely difficult to achieve a positive nitrogen balance in this group of patients $5,16,17,19$.

In summary, our study suggests that elevated ICP is associated with increased oxygen consumption, caloric expenditure, protein catabolism and overall hypermetabolism in severely head injured patient.

\section{Acknowledgements}

The authors thank the nursing staff of the Neurosurgical Intensive Care Unit for their valuable assistance. We also thank Miss Pat Frye for her typing assistance. 


\section{References}

1. Bartlett RH, Dechert RE, Mault JR, Clark SF (1984) Metabolic studies in chest trauma. J Thorac Cardiovasc Surg 87: 503-508

2. Bartlett RH, Dechert RE, Mault JR, Ferguson SK, Kaiser AM, Erlandson EE (1982) Measurement of metabolism in multiple organ failure. Surgery 92: 771-779

3. Bucci MN, Dechert RE, Arnoldi DK, Campbell J, McGillicuddy JE, Bartlett RH (1986) Metabolic requirements in patients with severe craniocerebral trauma. Surg Forum 37: 524-536

4. Clifton GL, Robertson CS, Choi SC (1986) Assessment of nutritional requirements of head-injured patients. J Neurosurg 64 : 895-901

5. Clifton GL, Robertson CS, Contant CF (1985) Enteral hyperalimentation in head injury. J Neurosurg 62: 186-193

6. Clifton GL, Robertson CS, Grossman RG, Hodge S, Foltz R, Garzac (1981) The metabolic response to severe head injury. J Neurosurg 60: 687-696

7. Clifton GL, Ziegler MG, Grossman RG, (1981) Circulating catecholamines and sympathetic activity after head injury. Neurosurgery $8: 10-14$

8. Deutschman CS, Konstantinides FN, Cera FB (1986) Hypermetabolism is not persistent in closed-head injury. Crit Care Med 14: 336

9. Deutschman CS, Konstantinides FN, Raup S, Thienprasit P, Cerra FB (1986) Physiological and metabolic response to isolated closed-head injury. J Neurosurg 64: 89-98

10. Drew JH, Koop CE, Grigger AB (1947) A nutritional study of neurosurgical patients. J Neurosurg 4: 7-15
11. Fruin AH, Taylon C, Pettis MS (1986) Caloric requirements in patients with severe head injuries. Surg Neurol 25: 25-28

12. Hadley MN, Graham TW, Harrington T, Schiller WR, McDermott MK, Posillico DB (1986) Nutritional support and neurotrauma: a critical review of early nutrition in forty-five acute head injury patients. Neurosurgery 19: 367-373

13. Kresowick TF, Dechert RE, Mault JR, Arnoldi DK, Whitehouse WM, Bartlett RH (1984) Does nutritional support affect survival in critically ill patients? Surg Forum 35: 108-110

14. Rapp RP, Young B, Twyman D, Bivins BA, Haack D, Tubbs PA, Bean JR (1983) The favorable effect of early parenteral feeding on survival in head-injured patients. J Neurosurg 58: 906-912

15. Turell DJ, Alexander JK (1964) Experimental evaluation of Weir's formula for estimating metabolic rate in man. J Appl Physiol 19: 946-948

16. Turner Jr WW (1985) Nutritional considerations in the patients with disabling brain disease. Neurosurgery 16: 707-713

17. Twyman D, Young AB, Ott L, Norton JA, Bivins BA (1985) High protein enteral feedings: a means of achieving positive nitrogen balance in head injured patients. J P E N 9: 679-684

18. Waters DC, Kocan MJ, Dechert RE, Bartlett RH (1984) Metabolic studies in head injury patients. Surg Forum 35: 482-483

19. Young B, Ott L, Norton J, Tibbs P, Rapp R, McClain C, Dempsey $R$ (1985) Metabolic and nutritional sequellae in the nonsteroid treated head injury patient. Neurosurgery 17: 784-791.

Correspondence and Reprints: Michael N. Bucci, M.D., 2128 Taubman Health Care Center - Box 0338, 1500 East Medical Center Drive, Ann Arbor, MI 48109, U.S.A. 